\title{
Effect of sperm DNA fragmentation on blastocyst formation rate and subsequent IVF outcome
}

\author{
Sankar Kumar Das, Krishna Kalita* \\ ART Department, Swagat Hospital and Research Centre, Bongaigaon, Assam, India
}

Received: 07 December 2021

Accepted: 03 January 2022

Accepted: 04 January 2022

\section{*Correspondence:}

Dr. Krishna Kalita,

E-mail: embryologist.swagat.bongai@gmail.com

Copyright: $\odot$ the author(s), publisher and licensee Medip Academy. This is an open-access article distributed under the terms of the Creative Commons Attribution Non-Commercial License, which permits unrestricted non-commercial use, distribution, and reproduction in any medium, provided the original work is properly cited.

\section{ABSTRACT}

Background: Male infertility associated with sperm DNA alteration has raised a new issue in assisted reproduction techniques (ARTs).

Methods: It was a retrospective analytical study on 250 cases of routine IVF/ICSI performed at Swagat ART Centre from January 2017 to January 2020. We divided the patient according to the sperm DNA fragmentation index (DFI) as normal $\mathrm{DFI} \leq 15 \%, \mathrm{n}=95$, a moderate $\mathrm{DFI} \leq 30 \%, \mathrm{n}=89$, and a high DFI group $>30 \%, \mathrm{n}=66$. Oocytes of each patient were almost equally divided and fertilization method was adopted as half IVF half ICSI or only ICSI in poor quality (oligo, astheno, teratozoospermia or with two or all three defect and compared the fertilization, cleavage, embryo formation, blastocyst formation, pregnancy and early embryo formation rate among these six groups.

Results: Fertilization, cleavage, embryo formation, and clinical pregnancy rates were reported as higher in $\leq 15 \%$ DFI group of both IVF and ICSI-ET (87.3 $\pm 26.2,77.7 \pm 26.1,68.2 \pm 28.8,50.8$ in IVF and 78.3 $\pm 17.8,70.3 \pm 31.2,67.2 \pm 28.8$, 57.6 respectively). Significant differences $(p<0.01)$ are observed among all six groups. Higher abortion rate is observed in high DFI group of both IVF and ICSI.

Conclusions: High sperm DFI causes low blastocyst formation and pregnancy outcome. Higher abortion rate observed in high DFI group indicated need of further study.

Keywords: DNA fragmentation, Sperm, IVF, ICSI outcome, Blastocyst formation

\section{INTRODUCTION}

Male infertility associated with sperm DNA alteration has raised a new issue in Assisted reproduction techniques (ARTs). Close relationship between DNA fragmentation and poor semen quality is reported by many researchers. Although, relationship between sperm DNA fragmentation and outcome of assisted reproduction treatment has been admitted, still it remains a subject of controversy. Some authors reported that high levels of DNA damage have been associated with decreased fertilization rates, embryo quality and pregnancy rates, while having no influence on reproductive outcome in other studies. ${ }^{1-4}$ This close relationship is particularly important in ARTs, where the sperm introduced is often selected by ICSI. It is reported that sperm DNA fragmentation significantly affects embryo post-implantation development in ICSI. Clinical pregnancy and pregnancy loss rates were significantly different in patients with high and low sperm DNA fragmentation. ${ }^{5}$

When the embryonic genome is participating in the metabolism of the embryo, it may cause reduction in the number of blastocysts with high DFI. Several authors have observed, using SCSA, or using TUNEL that higher DNA fragmentation causes a significantly lower pregnancy rate from IVF and/or ICSI treatment. ${ }^{6-8}$ The oocyte may also play a major role in determining the risks for pregnancy loss and frequencies of offspring with genetic defects of paternal origin as experimental evidence in a number of 
in-vivo and in-vitro systems reported that the vertebrate oocyte is capable of repairing endogenous and exogenous DNA damage. ${ }^{9,10}$

However, there is very little information on the possible consequences that fertilization, using sperm with deviating chromatin organization, may have impact on embryo development, implantation, gestation and offspring. ${ }^{11}$ The aim of the study was to find out the effect of sperm DNA fragmentation on fertilization, cleavage, blastocyst formation, implantation, pregnancy and abortion rate of normal female adopting both IVF and ICSI technique.

\section{METHODS}

It was a retrospective analytical study of 250 cases of routine IVF/ICSI-ET performed at Swagat ART Centre from January 2017 to January 2020. We divided the patient according to the sperm DNA fragmentation index (DFI) as normal DFI $\leq 15 \%, n=95$, a Moderate $\mathrm{DFI} \leq 30 \%, \mathrm{n}=89$, and a high DFI group $>30 \%, n=66$. Oocytes of each patient were almost equally divided and fertilization method were adopted as half IVF half ICSI or only ICSI in poor quality (oligo, astheno, teratozoospermia or with two or all three defects semen) and compared the fertilization, cleavage and blastocyst formation rate among these six group.

All female patients were $<42$ years of age. Only IVF and ICSI fresh cycles were reported. Semen samples were collected from men after they masturbated in the laboratory at 3 to 5 days abstinence. Semen samples were evaluated 15-30 minutes after collection for sperm motility, vitality, concentration, and morphology in accordance with the 2010 guidelines of the WHO.

Sperm DNA fragmentation was measured using a Sperm Chroma Kit. DFI was expressed as total number of sperm without halo/total number of sperm counter $\times 100$ with consideration of Normal reference value/Range for DFI index as (a) normal: DFI $<15 \%$; (b) good/fair: DFI $\geq 15 \%$ and $\mathrm{DFI} \leq 30 \%$; and (c) abnormal: DFI $>30 \%$.

Semen samples were prepared using pure sperm double layer $(40 \%$ and $80 \%)$ density gradient medium followed by swim-up method. A long down-regulation protocol was used for patients with normal ovarian reserve.

Patients with reduced reserve were stimulated with antagonist drug regimen and high starting dose of gonadotrophins. Follicular growth was monitored by ultrasound scans from day 7 of stimulation. When at least two leading follicles reached the diameter of $18 \mathrm{~mm}$ hCG was administered. Ovum pick-up (OPU) was planned 36 hr post-hCG injection.

Insemination was done after $4 \mathrm{hr}$ of OPU for IVF and for ICSI patients oocytes were denuded after $2 \mathrm{hr}$ of OPU followed by ICSI at 3 to $4 \mathrm{hr}$ respectively. Fertilization was evaluated at 18-20 hr post-insemination. Fertilization and embryo culture was done in Vitromed single-step medium covered by oil till blastocyst. Although single- step medium used, embryos were transferred to a new culture dishes in every alternate day.

Embryos were scored as per Istanbul embryo grading methods. Good quality embryos on D3 or blastocysts on day 5 (D5) were selected and transferred, and progesterone support was provided to the patient. Serum $\beta$-hCG levels were measured 14 days after embryo transfer.

Clinical pregnancy was confirmed by intrauterine pregnancy with a normal fetal heart rate seen on ultrasound 7-8 weeks after embryo transfer. Loss of the fetus within 12 weeks of pregnancy was classified as an early abortion.

\section{Statistical analysis}

Statistical analysis was done by using Microsoft excel version 2016.

\section{RESULTS}

\section{Effect of DFI on fertilization and cleavage rate}

Embryos with $2 \mathrm{PN}$ after 16-18 hr insemination were considered fertilized and the fertilization rate was calculated as the number of embryos with $2 \mathrm{PN}$ out of total no. oocytes inseminated or injected and it is represented as percentage. Cleavage rate was calculated as the percentage of the number of embryos at day 2 of the cycle having 4 or more cells per embryos out of the number of initial $2 \mathrm{PN}$ embryos. Result shows significant differences in fertilization and cleavage rate among groups $(p<0.01)$.

\section{Effect of DFI on blastocysts formation at day 5 after fertilization}

Total no. of blastocysts obtained out of cleaved embryos were observed at D5 and then considered for D5 blastocyst transfer to those patients whose cleavage stage embryo score were good and at-least 1-2 blastocyst were expected on D5. Results show lower blastocyst formation rate in higher DFI group irrespective of IVF or ICSI. There is significant difference $(\mathrm{p}<0.01)$ in blastocyst formation rate in between all groups.

\section{Effect of DFI on clinical pregnancy rate}

This result indicates that the sperm used for IVF or ICSI having a moderate $\mathrm{DFI} \leq 30 \%$ and a high DFI group $>30 \%$ DFI was associated with a lower clinical pregnancy rate than the sperm used for IVF or ICSI having a normal $\mathrm{DFI} \leq 15 \%$.

\section{Effect of DFI on abortion rate}

Results show lower pregnancy and higher abortion rate in high DFI $>30 \%$ group. Significant differences were observed in between groups. Percentage of pregnancy rate was higher in ICSI group. 
Table 1: The relationship between sperm DNA fragmentation index (DFI) and in vitro fertilization (IVF)/ Intracytoplasmic sperm injection (ICSI) outcome.

\begin{tabular}{|c|c|c|c|c|c|c|c|c|}
\hline \multirow{2}{*}{ DFI group } & \multicolumn{3}{|l|}{ IVF } & & \multicolumn{3}{|l|}{ ICSI } & \multirow[b]{2}{*}{$\mathbf{P}$} \\
\hline & $\leq 15 \%$ & $\leq 30 \%$ & $>30 \%$ & & $\leq 15 \%$ & $\leq 30 \%$ & $>30 \%$ & \\
\hline Cycle (N) & 45 & 40 & 30 & & 50 & 49 & 36 & \\
\hline Female age (years) & $32.3 \pm 5.0$ & $32.4 \pm 5.5$ & $33.1 \pm 5.8$ & 5.96 & $32.4 \pm 5.5$ & $31.3 \pm 5.0$ & $32.5 \pm 5.8$ & $<0.01$ \\
\hline Female BMI $\left(\mathrm{kg} / \mathrm{m}^{2}\right)$ & $22.9 \pm 3.1$ & $23.0 \pm 2.9$ & $22.7 \pm 3.0$ & 1.49 & $23.0 \pm 3.0$ & $22.7 \pm 3.1$ & $22.9 \pm 3.1$ & 1.49 \\
\hline Male age (years) & $36.8 \pm 5.3$ & $37.4 \pm 5.0$ & $37.8 \pm 5.2$ & 6.05 & $37.4 \pm 5.0$ & $36.8 \pm 5.3$ & $39.4 \pm 5.3$ & $<0.01$ \\
\hline DFI & 8 & 20 & 38 & 0.12 & $\begin{array}{l}8.4 \pm 3.6 \\
43.9 \pm 12.4\end{array}$ & $22.0 \pm 4.4$ & $40.9 \pm 12.4$ & $<0.01$ \\
\hline Ooc & $6.9 \pm 6.5$ & $5.1 \pm 5.6$ & $6.2 \pm 5.6$ & 0.01 & $6.8 \pm 4.9$ & $6.2 \pm 6.8$ & $7.2 \pm 6.8$ & $<0.01$ \\
\hline Ferti & $87.3 \pm 26.2$ & $78.2 \pm 25.8$ & $77.2 \pm 25.8$ & $<0.01$ & $78.3 \pm 17.8$ & $72.3 \pm 17.8$ & $70.3 \pm 17.8$ & $<0.01$ \\
\hline Cleava & $77.7 \pm 26.1$ & $74.3 \pm 27.2$ & $70.1 \pm 31.3$ & $<0.01$ & $70.3 \pm 31.2$ & $69.3 \pm 31.2$ & $65.3 \pm 31.2$ & $<0.01$ \\
\hline Good embryo rate (\%) & $68.2 \pm 28.8$ & $66.8 \pm 26.9$ & $58.2 \pm 28.8$ & $0 .<02$ & $67.2 \pm 28.8$ & $66.8 \pm 26.9$ & $56.8 \pm 26.9$ & $<0.01$ \\
\hline Blastocyst (N) & $2.1 \pm 2.5$ & $1.7 \pm 2.3$ & $1.5 \pm 2.0$ & $<0.01$ & $2.3 \pm 2.4$ & $1.8 \pm 2.7$ & $0.9 \pm 2.7$ & $<0.01$ \\
\hline Embryos n tran & $1.78 \pm 0.41$ & $1.71 \pm 0.46$ & $1.73 \pm 0.45$ & $<0.01$ & $1.79 \pm 0.40$ & $1.74 \pm 0.40$ & $1.70 \pm 0.40$ & $<0.01$ \\
\hline $\begin{array}{l}\text { Clinical pregnancy rate } \\
(\%)\end{array}$ & 50.8 & 45.7 & 43.2 & 1 & 57.6 & 62.3 & 51.4 & $<0.01$ \\
\hline Early abortion rate (\%) & 7.0 & 8.2 & 9.0 & $<0.01$ & 6.3 & 7.0 & 7.2 & $<0.01$ \\
\hline
\end{tabular}

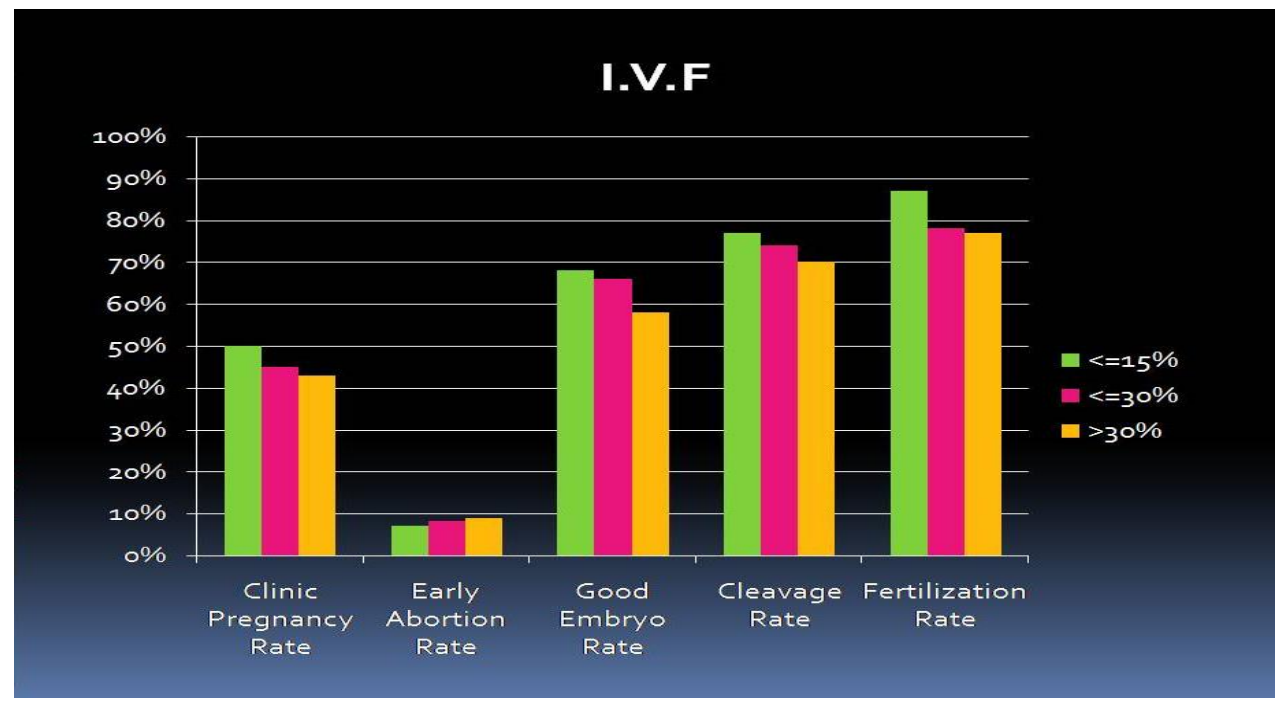

Figure 1: The relationship between sperm DNA fragmentation index (DFI) and In vitro fertilization (IVF) outcome.



Figure 2: The relationship between sperm DNA fragmentation index (DFI) and Intra cytoplasmic sperm injection (ICSI) outcome. 


\section{DISCUSSION}

Sperm DNA fragmentation (SDF) mostly occurs during spermatogenesis and maturation which can directly affect the sperm's normal functions. ${ }^{12}$ Three major factors known to cause sperm DNA damage are reported as abnormal sperm chromatin assembly, aberrant apoptosis of sperm cells, and excessive oxidative stress. ${ }^{13,14}$ Broken DNA fragments are produced in sperm cells as a result of damaged chromosomes and impaired DNA. ${ }^{15}$ During sperm maturation, histones are gradually replaced by the smaller arginine- and cysteine-rich protamine (HP), a process that reduces the ability of sperm DNA to repair itself in response to changes in the internal and external environments. ${ }^{14}$ Many investigators believe that SDF has a negative impact on embryo quality and pregnancy outcomes following IVF/ICSI. ${ }^{16,17}$

Studies found that high sperm DFI is not only related to reduced fertilization rate and poor embryo quality in IVF, but it is also associated with decreased rates of pregnancy. ${ }^{18}$ However, recent studies suggest that sperm DFI has no correlation with fertilization rates, and high DFIs do not affect the development of embryos or pregnancy outcomes following IVF/ICSI. ${ }^{4,19}$ In this study, we found that both the fertilization rates and the rates of good quality embryos decreased as the sperm DFI increased, there was significant difference in either rate between groups $(p<0.01)$. These results indicate that sperm DFI may be a predictor of the fertilization rate or embryo development, which is inconsistent with the conclusion of some other studies. ${ }^{19}$

Our study also bring into notice the relationship between sperm DNA fragmentation and early abortion. Our data seem to indicate that, in IVF, patients with high DNA fragmentation had significantly higher pregnancy loss rates compared to patients with low DNA fragmentation $(p<0.01)$. These data would seem to substantiate with some other studies evaluating the paternal influence on the etiology of early spontaneous miscarriage. ${ }^{20}$ The onset of biochemical pregnancy or early miscarriage may be the result of defective embryo formation due to the use of genetically abnormal sperm in paternal side.

The oocyte is able to trigger repair mechanisms in those cases where it recognizes the presence of sperm damaged DNA to some extent. Some authors reported an association between high DFI and abortion after ICSI. ${ }^{21,22}$ Our studies also observed high abortion rate in high DFI group irrespective of IVF/ICSI. However, ICSI cases showed comparatively lower abortion rate than IVF.

We hope that our findings would be an addition in this new insight of effect of sperm DNA fragmentation on IVF and ICSI outcomes.

However, prime limitations of our study were less no. of cases, single ART centre datas, financial, advanced laboratory as well as transportational facilities to carry out genectic studies on embryos etc.

\section{CONCLUSION}

In conclusion, our data indicate that sperm DNA fragmentation significantly affects embryo postimplantation development in both IVF and ICSI. Clinical pregnancy and pregnancy loss rates were significantly different in patients with high and low sperm DNA fragmentation. DNA fragmentation may compromise progression of pregnancy, resulting in spontaneous miscarriage following ART. In view of the importance of sperm DNA integrity, the actual cause of DNA damage needs to be assessed carefully with a view to identify proper therapeutic treatment. Furthermore, the development and correct use of methods for selecting sperm with undamaged DNA should also be ruled out.

\section{ACKNOWLEDGMENTS}

Special thanks to Dr. Atanu Basumatary for his kind help in statistical analysis part.

Funding: No funding sources

Conflict of interest: None declared

Ethical approval: The study was approved by the Institutional Ethics Committee

\section{REFERENCES}

1. Zini A, Boman JM, Belzile E, Ciampi A. Sperm DNA damage is associated with an increased risk of pregnancy loss after IVF and ICSI: systematic review and meta-analysis. Hum Reprod. 2008;23(12):2663-8.

2. Avendaño C, Franchi A, Duran H, Oehninger S. DNA fragmentation of normal spermatozoa negatively impacts embryo quality and intracytoplasmic sperm injection outcome. Fertil Steril. 2010;94(2):549-57.

3. Collins JA, Barnhart KT, Schlegel PN. Do sperm DNA integrity tests predict pregnancy with in vitro fertilization? Fertil Steril. 2008;89(4):823-31.

4. Lin MH, Kuo-Kuang LR, Li SH, Lu CH, Sun FJ, Hwu YM. Sperm chromatin structure assay parameters are not related to fertilization rates, embryo quality, and pregnancy rates in in vitro fertilization and intracytoplasmic sperm injection, but might be related to spontaneous abortion rates. Fertil Steril. 2008;90(2):352-9.

5. Borini A, Tarozzi N, Bizzaro D, Bonu MA, Fava L, Flamigni C, et al. Sperm DNA fragmentation: paternal effect on early post-implantation embryo development in ART. Hum Reprod. 2006;21(11):2876-81.

6. Cook KL, Brannian JD, Hansen KA, Kasperson KM, Aamold ET, Evenson DP. Relationship between the outcomes of assisted reproductive techniques and sperm DNA fragmentation as measured by the sperm chromatin structure assay. Fertil Steril. 2003;80(4):895-902. 
7. Henkel R, Kierspel E, Hajimohammad M, Stalf T, Hoogendijk C, Mehnert C, et al. DNA fragmentation of spermatozoa and assisted reproduction technology. Reprod Biomed Online. 2003;7(4):477-84.

8. Frydman N, Prisant N, Hesters L, Frydman R, Tachdjian G, Cohen-Bacrie P, et al. Adequate ovarian follicular status does not prevent the decrease in pregnancy rates associated with high sperm DNA fragmentation. Fertil Steril. 2008;89(1):92-7.

9. Marchetti F, Essers J, Kanaar R, Wyrobek AJ. Disruption of maternal DNA repair increases spermderived chromosomal aberrations. Proc Natl Acad Sci U S A. 2007;104(45):17725-9.

10. Smith MJ, Edwards RG. DNA repair by oocytes. Mol Hum Reprod. 1996;2(1):46-51.

11. Seli E, Sakkas D. Spermatozoal nuclear determinants of reproductive outcome: implications for ART. Hum Reprod Update. 2005;11(4):337-49.

12. Osman A, Alsomait H, Seshadri S, El-Toukhy T, Khalaf Y. The effect of sperm DNA fragmentation on live birth rate after IVF or ICSI: a systematic review and meta-analysis. Reprod Biomed Online. 2015;30(2):120-7.

13. Gomes M, Gonçalves A, Rocha E, Sá R, Alves A, Silva $\mathrm{J}$, et al. Effect of in vitro exposure to lead chloride on semen quality and sperm DNA fragmentation. Zygote. 2015;23(3):384-93.

14. Yang H, Li G, Jin H, Guo Y, Sun Y. The effect of sperm DNA fragmentation index on assisted reproductive technology outcomes and its relationship with semen parameters and lifestyle. Transl Androl Urol. 2019;8(4):356-65.

15. Barratt CL, Aitken RJ, Björndahl L, Carrell DT, Boer P, Kvist U, et al. Sperm DNA: organization, protection and vulnerability: from basic science to clinical applications--a position report. Hum Reprod. 2010;25(4):824-38.

16. Virro MR, Cook KL, Evenson DP. Sperm chromatin structure assay (SCSA) parameters are related to fertilization, blastocyst development, and ongoing pregnancy in in vitro fertilization and intracytoplasmic sperm injection cycles. Fertil Steril. 2004;81(5):1289-95.

17. Bounartzi T, Dafopoulos K, Anifandis G, Messini CI, Koutsonikou C, Kouris S, et al. Pregnancy prediction by free sperm DNA and sperm DNA fragmentation in semen specimens of IVF/ICSI-ET patients. Hum Fertil (Camb). 2016;19(1):56-62.

18. Zhang Y, Wang H, Wang L, Zhou Z, Sha J, Mao Y, et al. The clinical significance of sperm DNA damage detection combined with routine semen testing in assisted reproduction. Mol Med Rep. 2008;1(5):617-24.

19. Sun TC, Zhang Y, Li HT, Liu XM, Yi DX, Tian L, et al. Sperm DNA fragmentation index, as measured by sperm chromatin dispersion, might not predict assisted reproductive outcome. Taiwan J Obstet Gynecol. 2018;57(4):493-8.

20. Slama R, Bouyer J, Windham G, Fenster L, Werwatz A, Swan SH. Influence of paternal age on the risk of spontaneous abortion. Am J Epidemiol. 2005;161(9):816-23.

21. Borges E, Zanetti BF, Setti AS, Braga DPAF, Provenza RR, Iaconelli A. Sperm DNA fragmentation is correlated with poor embryo development, lower implantation rate, and higher miscarriage rate in reproductive cycles of non-male factor infertility. Fertil Steril. 2019;112(3):483-90.

22. Choi HY, Kim SK, Kim SH, Choi YM, Jee BC. Impact of sperm DNA fragmentation on clinical in vitro fertilization outcomes. Clin Exp Reprod Med. 2017;44(4):224-31.

Cite this article as: Das SK, Kalita K. Effect of sperm DNA fragmentation on blastocyst formation rate and subsequent IVF outcome. Int J Reprod Contracept Obstet Gynecol 2022;11:385-9. 